\title{
Gender-Role Attitudes and Reproductive Health Communication among Female Adolescents in South Nyanza, Kenya ${ }^{1}$
}

\section{Francis Obare}

Population Studies Center

University of Pennsylvania USA

\author{
Alfred Agwanda \\ PSRI \\ University of Nairobi \\ Kenya
}

\author{
Monica Magadi \\ CRSP \\ Loughborough University \\ United Kingdom
}

\begin{abstract}
In this paper, we use data from three districts of Nyanza Province in Kenya to examine gender-role attitudes and reproductive health communication among adolescent females aged 12-19 years. We test for differences in gender-role attitudes between younger (12-15) and older (16-19) adolescents. We explore the possible association between educational attainment and gender-role attitudes by estimating a randomeffects model. We also examine the association between gender-role attitudes and reproductive health communication via an unordered multinomial logit model. The results show that adolescent females in this setting hold conservative views on decision making within the home and at the same time portray less conservative views concerning marriage and reproductive behaviour. We also find some differences by age regarding gender-role attitudes and reproductive health communication. Our findings further indicate that educational attainment is significantly associated with gender-role attitudes, which in turn are significantly associated with reproductive health communication.
\end{abstract}

\section{Introduction}

The gendered nature of gender-role socialization of young people in much of the developing world and its implications for teenage reproductive health experiences are well recognized in the literature (see for example Gage 1998; Ahlberg et al., 2001; Machel, 2001; Varga, 2003; Marston, 2004). These patterns have persisted despite the rapid social, economic, political and cultural transformations that have taken place in these regions. There has been a weakening of the traditional family and community structures regarding sexual behaviours, beliefs and expectations (Rivers and Aggleton, 1999; Gueye et al., 2001). At the same time, studies show that the sexual attitudes and behaviour of young adolescents and adults in many parts of the developing world continue to be significantly shaped by socio-cultural and gender norms that convey contradictory messages about sexuality (Renne, 1993; Balk, 1997; Eggleston et al., 1999; Jewkes et al., 2001; Blanc, 2001; Mensch et al., 2003; Varga, 2003; Marston, 2004). These studies indicate that the socio-cultural and gender norms tend to define different standards of behaviour for boys and girls as well as men and women. 
Programs designed to provide the youth with sexual and reproductive health information in most settings of the developing world often have to overcome the challenges of deeply held cultural beliefs about sex, parenting, and the roles that men and women play (Rivers and Aggleton, 1999; and see for example Bawah et al., 1999; Campbell and MacPhail, 2002). It is therefore not surprising that recognizing these underlying beliefs and understanding how they manifest themselves as barriers to adolescent reproductive health programs are consistently pointed out in the literature as a priority if such programs are to register any success (e.g. Eggleston et al., 1999; Laub et al., 1999; Harrison et al. 2001; Ahlberg et al., 2001; Blanc, 2001; Varga, 2003). Existing literature suggests that current views among adolescents about sexuality, reproduction and decision making power within sexual relationships might portend future behaviour with regard to familial roles and reproduction (see for example Plotnick, 1992; Gueye et al., 2001; and Mensch et al., 2003). If this is the case, then addressing traditional genderrole attitudes that put social pressure on young boys to be sexually knowledgeable (hence sexually active) and on girls to remain poorly informed about sex (to maintain virginity) should form part of what adolescent sexual and reproductive health programs have to contend with.

In this paper, we investigate gender-role attitudes and reproductive health communication among adolescent females aged 12 to 19 years in three districts in South Nyanza region of Kenya. First, we explore whether younger female adolescents (those aged 12-15 years) are likely to portray gender-role attitudes that are significantly different from their older counterparts (those aged 16-19 years). Second, we examine the association between educational attainment and gender-role attitudes for this sample of adolescents. Third, we determine whether there is any association between communication about sex and sexual concerns on the one hand, and gender stereotype attitude on the other. We further investigate whether self-efficacy, i.e. the feeling that the respondent could use contraceptives even if parents or partners opposed it, is likely to be associated with both gender-role attitudes and reproductive health communication.

Our study is motivated by two important findings from previous research. The first finding is based on a study of gender-role attitudes among Egyptian adolescents by Mensch et al. (2003). They found that increased schooling was not associated with egalitarian gender-role attitudes. This is contrary to conventional wisdom that relates increased schooling to more egalitarian attitudes not only with regard to gender but also to health behaviour (e.g. Caldwell, 1993; Ross and Mirowsky, 1999). It is our contention that perhaps context might matter so that increased schooling might be important for gender-role attitudes in a different setting. The second finding is based on a study of gender, sexuality, and sexual and reproductive health communication among youth in the Philippines by 
Erickson et al. (2003). They found that traditional gender constructions and social norms inhibited discussion of sexual and reproductive health issues among youth, their parents and teachers. But we do not know whether similar conclusions can be reached in a different cultural context.

Evidence suggests that existing gender norms may determine who the adolescent talks to concerning matters of sexual nature and the content of such discussion (Kekovole et al., 1997; Gage, 1998; Gueye et al., 2001; Marston, 2004). At the same time, persons adolescents talk to concerning sexual and reproductive health matters may act to reinforce the existing gender norms (Barker and Rich, 1992; Gage 1998; Rivers and Aggleton, 1999; Gueye et al., 2001). In the following analysis, we make no attempt to disentangle the direction of these relationships owing to the cross-sectional nature of our data. Rather, we start from the point of view that gender-role attitudes and reproductive health communication are the attributes we want to explain. We subsequently pose a number of questions: Are there any significant differences between gender-role attitudes of younger compared to older female adolescents in the study setting? Does the relationship between education and gender-role attitudes among these adolescents confirm findings from other studies which go contrary to conventional wisdom? Are gender-role attitudes associated with reproductive health communication among this sample of adolescents?

There have been massive program efforts to empower the youth by providing them with the necessary reproductive health information especially in this era of HIV/AIDS (Rivers and Aggleton, 1999). We should, therefore, expect that these program efforts have enabled the youth to acquire greater sense of self-esteem and locus of control, and hence more egalitarian gender-role attitudes (Agha, 2003). However, we suspect that this might vary by settings depending on the differential impact of such programs. This is more relevant to the study setting where recent evidence from the 2003 Kenya Demographic and Health Survey (KDHS) shows that gender-role attitudes that are detrimental to the women's well-being are still the norm in the region (CBS, MOH, and ORC Macro 2004).

\section{Data and methods}

Data used for this paper are from a study in three districts of the South Nyanza region of Kenya, i.e. Homabay, Migori and Rachuonyo districts. The study, the Adolescent Safe Motherhood Survey (ASMS), was carried out between August and September 2002. The choice of the three districts was purely arbitrary based on the notion that they were predominantly Luo districts as opposed to Kuria which is a non-Luo district and Suba whose inhabitants are not purely Luo but have been assimilated by them. 
The overall objective of the study was to investigate the safe motherhood situation among adolescent females aged between 12 and 19 years in the South Nyanza region of Kenya.

Thirty-two clusters were randomly selected out of a total of 76 clusters in the three districts based on the national sampling frame developed by the Central Bureau of Statistics (CBS). Proportion allocation yielded twelve clusters each from Homabay and Migori districts and eight clusters from Rachuonyo district. All households within the selected clusters were included in the study to maximize the possibility of getting enough number of adolescent girls aged between 12 to 19 years.

About 1247 adolescent females were identified for individual interviews in the three districts and 1242 interviews were successfully completed. An individual questionnaire administered to eligible respondents captured information on their socio-economic and demographic characteristics, gender-role attitudes, and sexual and reproductive health knowledge and experience. Information was also collected on contraceptive use, approval and likely use in the face of opposition from parents/ partner, the pregnancy histories of those who had ever been pregnant as well as on obstetric morbidity experiences for the last pregnancy.

We first present simple descriptive statistics (percentages and means) of the distribution of respondents by gender-role attitudes and with whom they do discuss sexual concerns disaggregated by age i.e. younger (12-15) versus older (16-19 years) $)^{2}$. We further test for the significance of any observed differences between younger and older adolescents with regard to gender-role attitudes and self-efficacy.

We then estimate two models. The first is a random-effects model with the index of gender-role attitude as the dependent variable to take into account the fact that observations are not independent within clusters. The dependent variable is an additive index of a series of Likert type statements. While the responses were coded as $1=$ agree, $2=$ disagree and $3=$ no opinion, we have recoded the "agree" option to be zero and the "no opinion" option to be 1 so that the resulting index ranges from 0 to 14 . This sets the statements such that disagreement with all of them (index=14) would indicate the most egalitarian gender-role attitude while agreement with all of them (index $=0$ ) the least egalitarian attitudes. 
The second regression model is an unordered multinomial logic model ${ }^{3}$. The dependent variable is the person the respondents do talk to most regarding sexual concerns. These include parents, brothers, sisters, uncle/ aunts, other relatives, girlfriend, boyfriend/spouse, school teachers, and religious leaders. For modelling purposes and given that some of these categories had very few cases, we collapsed them into the following four categories: no one, other (includes brothers, sisters, uncles/aunts, other relatives, boyfriend/ spouse, school teacher, religious counsellor, and other), parents (father and mother), and peer girlfriend. This categorization is based on existing literature (e.g. De Weiss et al. 1991; Barker and Rich 1992) which

has mainly emphasized the distinctive role of peers and parents in the adolescent socialization process. In this model, we consider the index of gender-role attitudes as the covariate of interest.

In these models, we control for age, education level, an indicator of whether the respondent was still in school, living arrangements for the respondent, district of resident, and an index for wealth based on household possessions. Self-efficacy is also a variable of interest in the two models. The definition of these variables is given in Table 1.

Table 1: Definition of variables

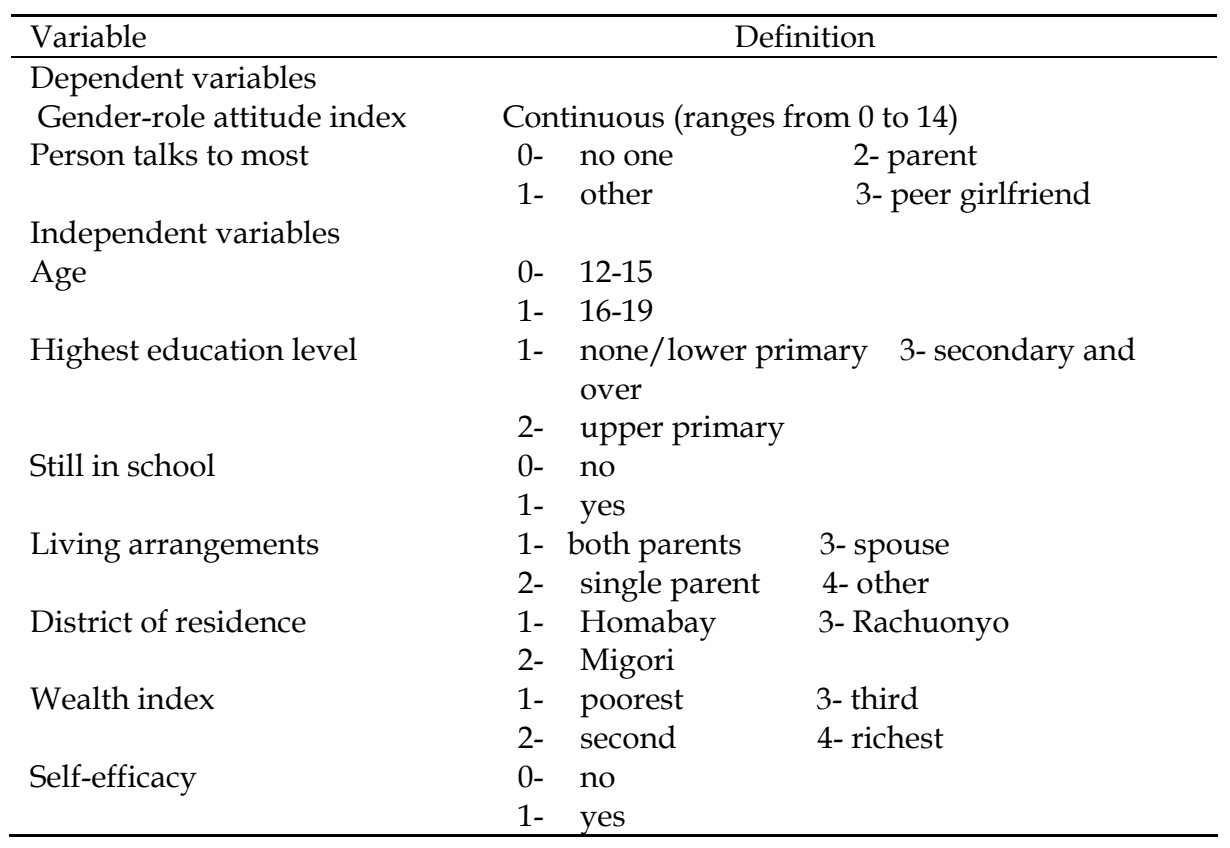




\section{Results}

\section{Distribution of Respondents by Gender-role Attitudes and Self-efficacy}

Table 2 shows the distribution of respondents by gender-role attitudes and self-efficacy according to age. Interestingly, a higher proportion of older adolescent females compared to younger ones agree with the statement that a woman needs a husband's permission for everything (about 87\% compared to about $79 \%$ ). The same applies to the statement that a woman differing with her husband must accept the husband's opinion (about 65\% versus about $60 \%$ ). The difference in the first case is statistically significant $(\mathrm{p}<0.01)$; it is not significant in the second case. Overall, about $83 \%$ of the respondents acknowledge that women have to seek permission from their spouses on what they need. About $62 \%$ agree that women must always let their husbands' decisions prevail. 
F.Obare A. Agwanda M. Magadi: Gender-Role Attitudes and Reproductive Health

Communication among Female Adolescents in South Nyanza Kenya

Table 2: Distribution of respondents by gender-role attitudes and self-efficacy, ASMS 2002.

\begin{tabular}{lcccc}
\hline & \multicolumn{4}{c}{ Percent agreeing with statement } \\
\cline { 2 - 5 } $\begin{array}{l}\text { Sounger } \\
\text { Statementa }\end{array}$ & $\begin{array}{c}\text { Older } \\
(16-19)\end{array}$ & $\begin{array}{c}\text { Total } \\
(12-19)\end{array}$ & $\begin{array}{c}\text { Significance } \\
\text { of } \\
\text { difference }\end{array}$ \\
\hline $\begin{array}{l}\text { Woman needs husband's } \\
\text { permission for everything }\end{array}$ & 79.4 & 86.7 & 82.8 & $* *$ \\
$\begin{array}{l}\text { Woman differing must } \\
\text { accept husband's opinion }\end{array}$ & 59.8 & 64.6 & 62.0 & NS \\
$\begin{array}{l}\text { An illiterate girl's best } \\
\text { option is to get married }\end{array}$ & 25.6 & 27.0 & 26.2 & NS \\
$\begin{array}{l}\text { If a boy asks and the parent } \\
\text { agrees for marriage the girl } \\
\text { has no choice }\end{array}$ & 36.7 & 27.3 & 32.4 & $*$ \\
$\begin{array}{l}\text { If a man wants children the } \\
\text { wife has to comply }\end{array}$ & 45.0 & 43.4 & 44.3 & NS \\
$\begin{array}{l}\text { If a woman has not had a } \\
\text { boy child she has to keep on } \\
\text { trying }\end{array}$ & 38.8 & 32.2 & 35.8 & $*$ \\
$\begin{array}{l}\text { If a woman does not have a } \\
\text { girl child she has to keep on } \\
\text { trying }\end{array}$ & 37.6 & 31.4 & 34.7 & $*$ \\
\hline & & & & \\
\hline $\begin{array}{l}\text { Gender-role attitude index } \\
\text { (0-14) }\end{array}$ & 7.3 & 7.5 & 7.4 & NS \\
\hline
\end{tabular}

\begin{tabular}{lllll} 
& \multicolumn{4}{c}{ Percent distribution by self-efficacy indicator } \\
\hline $\begin{array}{l}\text { Would use contraceptives } \\
\text { despite parental/ partner } \\
\text { opposition }\end{array}$ & 28.1 & 56.7 & 41.2 & $* *$ \\
\hline
\end{tabular}

Notes: $\quad$ For the seven items on gender-role attitudes, the mean inter-item correlation is 0.24 ; minimum $=0.11$; maximum $=0.78$; variance $=0.02$; reliability alpha $=0.69$. ${ }^{*} \mathrm{p}<0.05 ;{ }^{* *} \mathrm{p}<0.01 ; \mathrm{NS}=$ not significant. 
The response patterns with regard to marriage and reproductive behaviour however differ. Higher proportions of younger adolescent females compared to their older counterparts agree with the statements about marriage and reproduction. But the difference is not statistically significant for the statement that if a man wants children, the wife has to comply. The proportions of respondents agreeing with these statements are also lower than those agreeing with statements about decision making. Overall, there is no significant difference in the mean gender-role attitude index score for younger compared to older adolescents. But we see a statistically significant difference $(p<0.01)$ by age in the proportion of respondents who indicate that they would still use contraceptives even if their parents or partners were to refuse. Older adolescents are more likely than their younger counterparts to portray some sense of self-efficacy.

\section{Distribution of Respondents by Reproductive Health Communication}

Table 3 shows the distribution of respondents by whether they do discuss matters pertaining to sex with the various members of the social contact. The percentages in columns 2 to 4 of the table are based on the question that allowed for multiple responses. These percentages are computed according to the number of cases responding yes for each member of the social contact for the given age group. The mother emerges as the most preferred member of the family group (about $50 \%$ for younger and $35 \%$ for older adolescents). The peer friend is the most preferred other member of the social group other than the immediate family member (about $52 \%$ for younger and $56 \%$ for older adolescents). Overall, the peer friend is the most preferred member of the social contact for discussing sexual matters. This is followed by the mother while male members of the social contact groups rank low. The teacher and the religious counsellor are some of the least preferred. 
F.Obare A. Agwanda M. Magadi: Gender-Role Attitudes and Reproductive Health Communication among Female Adolescents in South Nyanza Kenya

Table 3: Percent distribution of respondents according to whether they discuss concerns of sexual nature with the given individual, ASMS 2002.

\begin{tabular}{|c|c|c|c|c|c|c|}
\hline \multirow[b]{2}{*}{ Person talks to } & \multicolumn{3}{|c|}{ Percent of cases "yes" a } & \multicolumn{3}{|c|}{ Person talks to most (percent) ${ }^{b}$} \\
\hline & $\begin{array}{l}\text { Younge } \\
\text { r (12-15) }\end{array}$ & $\begin{array}{r}\text { Older } \\
(16- \\
19)\end{array}$ & $\begin{array}{r}\text { Total } \\
(12- \\
19)\end{array}$ & $\begin{array}{r}\text { Younger } \\
(12-15)\end{array}$ & $\begin{array}{c}\text { Older } \\
(16-19)\end{array}$ & $\begin{array}{c}\text { Total } \\
(12-19)\end{array}$ \\
\hline Father & 13.5 & 6.8 & 10.3 & 2.1 & 0.7 & 1.4 \\
\hline Mother & 49.6 & 34.7 & 42.7 & 34.9 & 18.6 & 27.4 \\
\hline Brother & 8.0 & 6.1 & 7.1 & 0.6 & 0.9 & 0.7 \\
\hline Sister & 31.2 & 23.5 & 27.7 & 11.2 & 9.1 & 10.3 \\
\hline Uncle/ aunt & 10.8 & 8.1 & 9.5 & 3.4 & 1.9 & 2.7 \\
\hline Other relative & 16.4 & 20.3 & 18.2 & 5.6 & 7.7 & 6.6 \\
\hline Girlfriend & 52.4 & 55.7 & 53.9 & 25.7 & 28.6 & 27.0 \\
\hline $\begin{array}{l}\text { Boyfriend/spo } \\
\text { use }\end{array}$ & 5.5 & 34.3 & 18.7 & 2.8 & 19.8 & 10.6 \\
\hline School teacher & 5.2 & 3.0 & 4.2 & 0.9 & 0.9 & 0.9 \\
\hline $\begin{array}{l}\text { Religious } \\
\text { counsellor }\end{array}$ & 0.7 & 0.9 & 0.8 & 0.2 & 0.2 & 0.2 \\
\hline Other person & 3.6 & 4.0 & 3.8 & 1.3 & 1.4 & 1.4 \\
\hline No one & 11.8 & 10.9 & 11.4 & 11.2 & 10.3 & 10.8 \\
\hline $\begin{array}{l}\text { Number of } \\
\text { cases }\end{array}$ & 676 & 571 & 1247 & 676 & 571 & 1247 \\
\hline
\end{tabular}

The percentages in columns 5 to 7 of Table 3 are based on the responses to the question about the person the respondents do talk to most and thus allowed for only one response per individual. For younger adolescents, the mother was the most preferred followed by the peer friend (about $35 \%$ and $26 \%$ respectively). For their older counterparts, the peer friend was the most preferred followed by the mother (about 29\% and 19\% respectively). Overall, however, there is no difference between preference for the mother and the peer friend (about $27 \%$ in each case) if we consider all respondents together. This overall lack of difference in the preference for the mother and the peer friend therefore masks the differences by age. 


\section{Educational Attainment and Gender-role Attitudes}

Table 4 gives the results from the ordinary least squares (OLS), fixed-effects, and the preferred random-effects models examining the association between educational attainment and gender-role attitudes in addition to other covariates. Those with upper primary as well as secondary and above levels of education are significantly more likely to hold more egalitarian genderrole attitudes compared to those with no or lower primary level of education.

Table 4: OLS, fixed-effects and random-effects regression coefficients for the correlates of gender-role attitudes, ASMS 2002.

\begin{tabular}{|c|c|c|c|}
\hline Covariates & $\begin{array}{c}\text { OLS } \\
\text { Estimatesa }\end{array}$ & $\begin{array}{c}\text { Fixed-effects } \\
\text { estimatesb }^{b}\end{array}$ & $\begin{array}{l}\text { Random- } \\
\text { effects } \\
\text { estimatesc }\end{array}$ \\
\hline \multicolumn{4}{|l|}{ Education level } \\
\hline \multicolumn{4}{|l|}{ None/lower primary ${ }^{R}$} \\
\hline Upper primary & $0.721^{* *}(0.244)$ & $0.578 *(0.248)$ & $0.645^{\star *}(0.245)$ \\
\hline Secondary and above & $3.158^{* *}(0.404)$ & $2.932 * *(0.414)$ & $3.031^{* *}(0.406)$ \\
\hline Self-efficacy (yes=1) & $0.039(0.129)$ & $-0.293(0.212)$ & $-0.265(0.209)$ \\
\hline \multicolumn{4}{|l|}{ Age } \\
\hline \multicolumn{4}{|l|}{$12-15^{\mathrm{R}}$} \\
\hline $16-19$ & $-0.040(0.256)$ & $0.052(0.258)$ & $0.013(0.255)$ \\
\hline Currently in school (yes=1) & $0.183(0.300)$ & $0.168(0.308)$ & $0.189(0.303)$ \\
\hline \multicolumn{4}{|l|}{ Living arrangements } \\
\hline \multicolumn{4}{|l|}{ Both parents ${ }^{R}$} \\
\hline Single parent & $0.155(0.262)$ & $0.135(0.265)$ & $0.137(0.262)$ \\
\hline Spouse & $-0.508(0.380)$ & $-0.567(0.382)$ & $-0.535(0.379)$ \\
\hline Other & $0.242(0.271)$ & $0.126(0.276)$ & $0.173(0.272)$ \\
\hline \multicolumn{4}{|l|}{ District } \\
\hline \multicolumn{4}{|l|}{ Homabay ${ }^{\mathrm{R}}$} \\
\hline Migori & $-0.363(0.235)$ & & $-0.325(0.342)$ \\
\hline Rachuonyo & $0.056(0.257)$ & & $0.002(0.377)$ \\
\hline \multicolumn{4}{|l|}{ Wealth index } \\
\hline \multicolumn{4}{|l|}{ Poorest quartile ${ }^{R}$} \\
\hline Second quartile & $0.319(0.299)$ & $0.196(0.309)$ & $0.265(0.303)$ \\
\hline Third quartile & $0.732 *(0.300)$ & $0.457(0.344)$ & $0.596(0.318)$ \\
\hline Richest quartile & $0.441(0.301)$ & $0.069(0.359)$ & $0.266(0.325)$ \\
\hline
\end{tabular}

Notes: Higher values of gender-role attitudes correspond to more egalitarian attitudes; standard errors are given in parentheses.

aEstimates do not take into account unobserved cluster characteristics which may also influence gender-role attitudes.

bEstimates take into account unobserved cluster characteristics but assume that these characteristics are fixed; there are no fixed-effects estimates for district because this factor does not vary within clusters.

cEstimates take into account unobserved cluster characteristics but assume that these are randomly distributed. This is our preferred model after testing for the plausibility of its assumptions.

RReference category; ${ }^{*} \mathrm{p}<0.05 ;{ }^{* *} \mathrm{p}<0.01$. 
There is also a significant difference in gender-role attitudes between those with upper primary education and those with secondary and above education. Those in the latter category are significantly more likely to hold egalitarian gender-role attitudes $(p<0.01)$. Overall, and regardless of the model, education is significantly associated with gender-role attitudes $(p<0.01)$. The only other significant difference we observe is that between those living with the spouse and those living with other persons. In this case, those living with other persons are significantly more likely to hold egalitarian gender-role attitudes $(\mathrm{p}<0.05)$.

\section{Gender-role Attitudes and Reproductive Health Communication}

The results in Table 5 are from the unordered multinomial logit model with the person the respondents do talk to most as the dependent variable. The reference category for the dependent variable is the peer friend. Gender-role attitude is only significant $(\mathrm{p}<0.01)$ for the difference between talking to other persons versus talking to a peer friend. Those with more egalitarian gender-role attitudes are significantly less likely to talk to other persons as opposed to talking to a peer friend. Self-efficacy is also significant for the difference between talking to parents and peer friend $(p<0.01)$, and that between talking to other persons and peer friend $(p<0.05)$. In both cases, the coefficients are negative. This implies that those with a higher sense of locus of control are significantly less likely to talk to parents or other persons as opposed to talking to the peer friend regarding sexual concerns. 
http://aps.journals.ac.za

48 African Population Studies Vol. $21 n^{\circ} 1 /$ Etude de la population africaine vol. $21 n^{\circ} 1$

Table 5: Multinomial logic regression coefficients for the correlates of reproductive health communication, ASMS 2002.

\begin{tabular}{|c|c|c|c|}
\hline \multirow[b]{2}{*}{ Covariates } & \multicolumn{3}{|c|}{ Person talks to most versus peer girl frienda } \\
\hline & Parent & Other persons & No one \\
\hline Gender-role attitudes & $0.018(0.029)$ & $-0.060^{* *}(0.016)$ & $\begin{array}{c}0.024 \\
(0.024)\end{array}$ \\
\hline Self-efficacy (yes=1) & $-0.536^{* *}(0.163)$ & $-0.304^{*}(0.149)$ & $\begin{array}{l}-0.411 \\
(0.225)\end{array}$ \\
\hline \multicolumn{4}{|l|}{ Education level } \\
\hline Upper primary & $0.362^{*}(0.166)$ & $0.355(0.191)$ & $\begin{array}{l}-0.246 \\
(0.194)\end{array}$ \\
\hline Secondary and above & $0.274(0.348)$ & $0.416(0.333)$ & $\begin{array}{c}0.033 \\
(0.393)\end{array}$ \\
\hline \multicolumn{3}{|l|}{ Age } & \\
\hline $16-19$ & $-0.743^{* *}(0.175)$ & $-0.153(0.201)$ & $\begin{array}{l}-0.213 \\
(0.274)\end{array}$ \\
\hline $\begin{array}{l}\text { Currently in school } \\
(\text { yes=1) }\end{array}$ & $-0.213(0.221)$ & $-0.259(0.241)$ & $\begin{array}{l}-0.261 \\
(0.309)\end{array}$ \\
\hline \multicolumn{4}{|l|}{ Living arrangements } \\
\hline Single parent & $0.050(0.186)$ & $-0.211(0.238)$ & $\begin{array}{c}0.094 \\
(0.356)\end{array}$ \\
\hline Spouse & $-0.704(0.372)$ & $1.296^{* *}(0.283)$ & $\begin{array}{c}0.548 \\
(0.427)\end{array}$ \\
\hline Other & $-0.784^{* *}(0.205)$ & $0.528^{*}(0.232)$ & $\begin{array}{c}0.292 \\
(0.332)\end{array}$ \\
\hline \multicolumn{4}{|l|}{ District } \\
\hline Migori & $0.320(0.210)$ & $0.149(0.165)$ & $\begin{array}{c}0.254 \\
(0.268)\end{array}$ \\
\hline Rachuonyo & $0.850^{* *}(0.250)$ & $0.244(0.180)$ & $\begin{array}{l}-0.248 \\
(0.259)\end{array}$ \\
\hline \multicolumn{4}{|l|}{ Wealth index } \\
\hline Second quartile & $0.159(0.293)$ & $0.597^{*}(0.269)$ & $\begin{array}{l}0.936^{* *} \\
(0.338)\end{array}$ \\
\hline Third quartile & $0.236(0.238)$ & $0.543^{*}(0.238)$ & $\begin{array}{c}0.402 \\
(0.352)\end{array}$ \\
\hline Richest quartile & $0.488(0.274)$ & $0.555^{*}(0.242)$ & $\begin{array}{c}0.245 \\
(0.331)\end{array}$ \\
\hline
\end{tabular}

Notes: $\quad$ The reference category for the dependent variable is peer girlfriend; robust standard errors are in parentheses; estimates take account of clustering of observations. RReference category; ${ }^{*} \mathrm{p}<0.05 ;{ }^{* *} \mathrm{p}<0.01$. 
An overall test of significance of the coefficients for gender-role attitudes and self-efficacy in the full model shows that they are significant (for the coefficients of gender-role attitudes $(p<0.01)$; for the coefficients of selfefficacy $(p<0.01)$. Thus, these two factors are significantly associated with reproductive health communication. The other significant factors in the overall tests of significance of the coefficients in the full model are living arrangements $(p<0.01)$, district of residence $(p<0.01)$, and the wealth index $(p<0.01)$. The coefficients for living arrangements are in the expected direction if we consider talking to parents versus peer friend, or other persons versus the peer friend. District differentials show that those living in Rachuonyo District are significantly more likely to talk to parents as opposed to talking to the peer friend compared to those from Homabay District $(p<0.01)$. While there is no difference between Migori and Homabay Districts in this respect, the difference between Migori and Rachuonyo is significant $(\mathrm{p}<0.05)$.

\section{Discussion}

A previous study by Mensch et al. (2003) indicates that schooling does not always promote egalitarian attitudes. This is contrary to other existing evidence which shows that schooling is associated with more egalitarian attitudes and better health behaviours (e.g. Caldwell, 1993; Ross and Mirowsky, 1999). We have argued that the context matters for the association between schooling and gender-role attitudes among youth. Our study among female adolescents aged 12-19 years in three districts in the South Nyanza region of Kenya shows that educational attainment is significantly associated with gender-role attitudes among youth in this setting. Higher educational attainment is associated with more egalitarian gender-role attitudes.

Two possible conclusions can be drawn from this finding. First, it could be that schooling is associated with gender-role attitudes but only after a certain level of schooling is attained. Second, it could be the case that the relationship between schooling and gender-role attitudes is different in different cultural contexts, an indication that context matters for the relationship. But it points to the need for increased emphasis on the education of the girl-child in this setting as a way of challenging the traditional gender norms and beliefs that disadvantage women. 
The results on gender-role attitudes further reveal a contradictory pattern in which adolescent girls in this region are still more likely to hold conservative views with regard to decision making within the household while at the same time showing more egalitarian views concerning marriage and reproductive behaviour. One surprising finding is the tendency for older adolescent females to portray more conservative views concerning decision making within the household compared to their younger counterparts. It could partly be a reflection of how young women in the study area are socialized i.e. to be submissive to their husbands, or it may reflect the daily experiences of these teenagers in their homes. It therefore appears that for adolescent sexual and reproductive health programs in this region, challenging gender norms that deny young women the right to make decisions would be of first priority before those that stress marriage and reproductive behaviour.

Other studies also show that traditional gender constructions and social norms hinder discussion of sexual and reproductive health issues among youth and their parents or teachers (Erickson et al. 2003). But would the relationship hold in a different cultural context? Our results confirm that, overall, gender-role attitude is significantly associated with reproductive health communication. This significance appears to be largely driven by the significant difference between talking to other persons as opposed to the peer friend. In such a case, adolescents with more egalitarian gender-role attitudes in this setting are less likely to discuss sexual concerns with other persons compared to their peer friends.

The implication of this finding is that it is possible that gender-role attitudes matter only for discussing sexual matters with specific members of the social contact and not others. This could be the case if the adolescent socialization process emphasizes discussion of sexual matters with specific members of the social contact as has been traditionally the case in much of sub-Saharan Africa (see for example Gage, 1998; Gueye et al., 2001). The conclusion is however similar to that observed in other settings (e.g. by Erickson et al., 2003) that gender-role attitudes are associated with discussion of sexual concerns with members of the social contact.

The results also indicate that generally, younger adolescent females prefer most talking to the mother about sexual concerns while older ones prefer peer friend. This may reflect the fact that younger adolescents are more likely to be living with their parents compared to their older counterparts. But it implies that young adolescent girls who do not live with their mothers are more likely to be in difficult position with regard to discussing their reproductive health concerns. There is also a gender-based 
socialization process in which there is little communication between the girls and their brothers and similarly between the girls and their fathers. The teachers and the religious group are a distant group despite the distinctive call for sex education in schools. It implies that while schools may provide knowledge, the psychological predisposition to talk about emotive issues like sex, especially for this sample of adolescent females, lies with the mother and the peer friend.

We also find that overall, living arrangements and the district of residence are significant factors associated with discussion of sexual concerns with other members of the social contact. The findings about living arrangements are indicative of the intuition that persons would be more inclined to discuss matters of concern- sexual or otherwise- with those in their immediate environments. The overall significance of district of residence seems to be mostly accounted for by its significant association with discussion of sexual concerns with parents as opposed to peer friends. Those from Rachuonyo District are significantly more likely to discuss sexual concerns with parents as opposed to peer friends compared to those from Homabay District. The same applies to the comparison between Rachuonyo and Migori Districts. But we do not find any significant difference between Homabay and Migori Districts in this respect.

Finally, we fail to find any significant association between the indicator for self-efficacy and gender-role attitudes. Though the association is positive as we would expect, it is not statistically significant. We however find significant association between self-efficacy and reproductive health communication when the choice is to be made between discussing sexual concerns with parents and with other persons as opposed to peer friends. In both cases, the association is negative implying that those with some sense of self-esteem and locus of control are significantly less likely to discuss sexual concerns with the parents or other persons as opposed to their peer friends.

\section{Conclusion}

Despite the limitations posed by cross-sectional data, our findings show that adolescent females in the study districts still hold conservative views regarding decision making within the home. These conservative views confer men with the power to make decisions some of which affect women's well-being as well. At the same time, views on marriage and reproductive behaviour tend to be less conservative. Thus, reproductive health programs aimed at empowering youth in this setting would need to consider the challenges posed by long-held beliefs about male dominance of decision making in the home. 
We further find differences by age regarding members of the social contact with whom the adolescent females do mostly discuss sexual concerns. The younger ones tend to give first preference to the mother while their older counterparts tend to give first priority to the peer friend. It is therefore plausible to argue that programs for youth in this setting may do well by adopting a two-thronged approach targeting mothers of younger adolescents and peers of older adolescents. But it remains an open question whether peer-based programs are better-off within the school environment. This is because of the possible prerequisite to involve teachers under such circumstances and given that teachers rank lowest among those whom adolescent females in this setting are likely to discuss sexual concerns with. But schooling is important for promoting egalitarian gender-role attitudes which in turn have implications for reproductive health communication among female adolescents in the study setting.

\section{Notes}

1. The study on which this paper is based was funded by the World Health Organization (WHO). It was carried out by the African Population and Health Research Center (APHRC), Nairobi, in collaboration with the Opportunities and Choices Reproductive Health Programme of the University of Southampton, and the Population Studies and Research Institute of the University of Nairobi. We also acknowledge the roles of the District Statistical Officers (DSOs) of the three districts where the study was conducted and members of the fieldwork team for their contribution toward the successful completion of the study that provided the data for this paper.

2. The grouping of age into $12-15$ and $16-19$ years is based on the legal age of sexual consent (16 years) in the country.

3. Robust standard errors are estimated. The model also takes into account the clustering of observations within clusters. We achieve these in STATA software program (version 8.0) by using the "robust" and "cluster" options with the "mlogic" command. 


\section{References}

Agha, S. 2003. "The impact of mass media campaign on personal risk perception, perceived self-efficacy and on other behavioural predictors." AIDS Care 15, (6): 749-762.

Ahlberg, B.M., Jylkäs, E. and Krantz, I. 2001. “Gendered construction of sexual risks: implications for safer sex among young people in Kenya and Sweden." Reproductive Health Matters 9, (17): 26-35.

Balk, D. 1997. “Defying Gender Norms in Rural Bangladesh: A Social Demographic Analysis." Population Studies 51, (2): 153-172.

Barker, G.K. and Rich, S. 1992. "Influences on Adolescent Sexuality in Nigeria and Kenya: Findings from Recent Focus-Group Discussions." Studies in Family Planning 23, (3): 199-210.

Bawah, A.A., Akweongo, P., Simmons, R. and Phillips, J.F. 1999. “Women's Fears and Men's Anxieties: The Impact of Family Planning on Gender Relations in Northern Ghana." Studies in Family Planning 30, (1): 54-66.

Blanc, A.K. 2001. "The Effect of Power in Sexual Relationships on Sexual and Reproductive Health: An Examination of the Evidence." Studies in Family Planning 32, (3): 189-213.

Caldwell, J.C. 1993. "Health Transition: The Cultural, Social and Behavioural Determinants of Health in the Third World." Social Science and Medicine 36, (2): 125-135.

Campbell, C. and MacPhail, C. 2002. "Peer education, gender and the development of critical consciousness: participatory HIV prevention by South African youth." Social Science and Medicine 55: 331-345.

Central Bureau of Statistics (CBS) [Kenya], Ministry of Health (MOH) [Kenya], and ORC Macro. 2004. Kenya Demographic and Health Survey 2003. Calverton, Maryland: CBS, $\mathrm{MOH}$, and ORC Macro.

De Weiss, S.P., Atkin, L.C., Gribble, J.N. and Andrade-Palos, P. 1991. “Sex, Contraception, and Pregnancy Among Adolescents in Mexico City." Studies in Family Planning 22, (2): 74-82.

Eggleston, E., Jackson, J. and Hardee, K. 1999. “Sexual Attitudes and Behavior Among Young Adolescents in Jamaica." International Family Planning Perspectives 25, (2): 78-84 \& 91.

Erickson, P.I., Badiane, L., Ramos-Jimenez, P. and Loganathan, R. 2003.

"Gender, sexuality, and communication about sexual and reproductive health among Filipino youth." Paper presented at the Annual Meeting of the American Public Health Association (APHA), 15-19 November.

Gage, A.J. 1998. "Sexual Activity and Contraceptive Use: The Components of the Decisionmaking Process." Studies in Family Planning 29, (2): 154-166.

Gueye, M., Castle, S. and Konate, M.K. 2001. “Timing of First Intercourse among Adolescents: Implications for Contraceptive Use." International Family Planning Perspectives 27, (2): 56-62 \& 70.

Harrison, A., Xaba, N. and Kunene, P. 2001. “Understanding safe sex: gender narratives of HIV and pregnancy prevention by rural South African schoolgoing youth." Reproductive Health Matters 9, (17): 63-71.

Jewkes, R., Vundule, C., Maforah, F. and Jordaan, E. 2001. “Relationship dynamics and teenage pregnancy in South Africa." Social Science and Medicine 52: 733-744. 
54 African Population Studies Vol. $21 n^{\circ}$ 1/Etude de la population africaine vol. $21 n^{\circ} 1$

Kekovole, J., Kiragu, K., Muruli, L. and Josiah, P. 1997. Reproductive Health Communication in Kenya: Results of a National Information, Education, and Communication Situation Survey.

Laub, C., Somera, D.M., Gowen, L.K. and Diaz, R.M.. 1999. “Targeting "Risky" Gender Ideologies: Constructing a Community-driven, Theory-based HIV Prevention Intervention for Youth." Health Education \& Behavior 26, (2): 185-199.

Machel, J.Z. 2001. “Unsafe sexual behaviour among schoolgirls in Mozambique: a matter of gender and class." Reproductive Health Matters 9, (17): 82-90.

Marston, C. 2004. "Gendered communication among young people in Mexico: implications for sexual health interventions." Social Science and Medicine 59: 445-456.

Mensch, B.S., Ibrahim, B.L., Lee, S.M. and El-Gibaly, O. 2003. “Gender-role Attitudes among Egyptian Adolescents." Studies in Family Planning 34, (1): 8-18.

Plotnick, R.D. 1992. “The Effects of Attitudes on Teenage Premarital Pregnancy and its Resolution." American Sociological Review 57, (6): 800-811.

Renne, E.P. 1993. “Gender Ideology and Fertility Strategies in an Ekiti Yoruba Village." Studies in Family Planning 24, (6): 343-353.

Rivers, K. and Aggleton, P. 1999. Adolescent Sexuality, Gender and the HIV Epidemic. UNDP, London: HIV and Development Programme.

Ross, C.E. and Mirowsky, J. 1999. "Refining the Association between Education and Health: The Effects of Quantity, Credential, and Selectivity." Demography 36, (4): 445-460.

Varga, C.A. 2003. "How Gender Roles Influence Sexual and Reproductive Health Among South African Adolescents." Studies in Family Planning 34, (3): 160-172. 